\title{
LA UNIVERSIDAD LATINOAMERICANA Y EL SIGLO XXI
}

\author{
Máximo Chaparro Schetti*
}

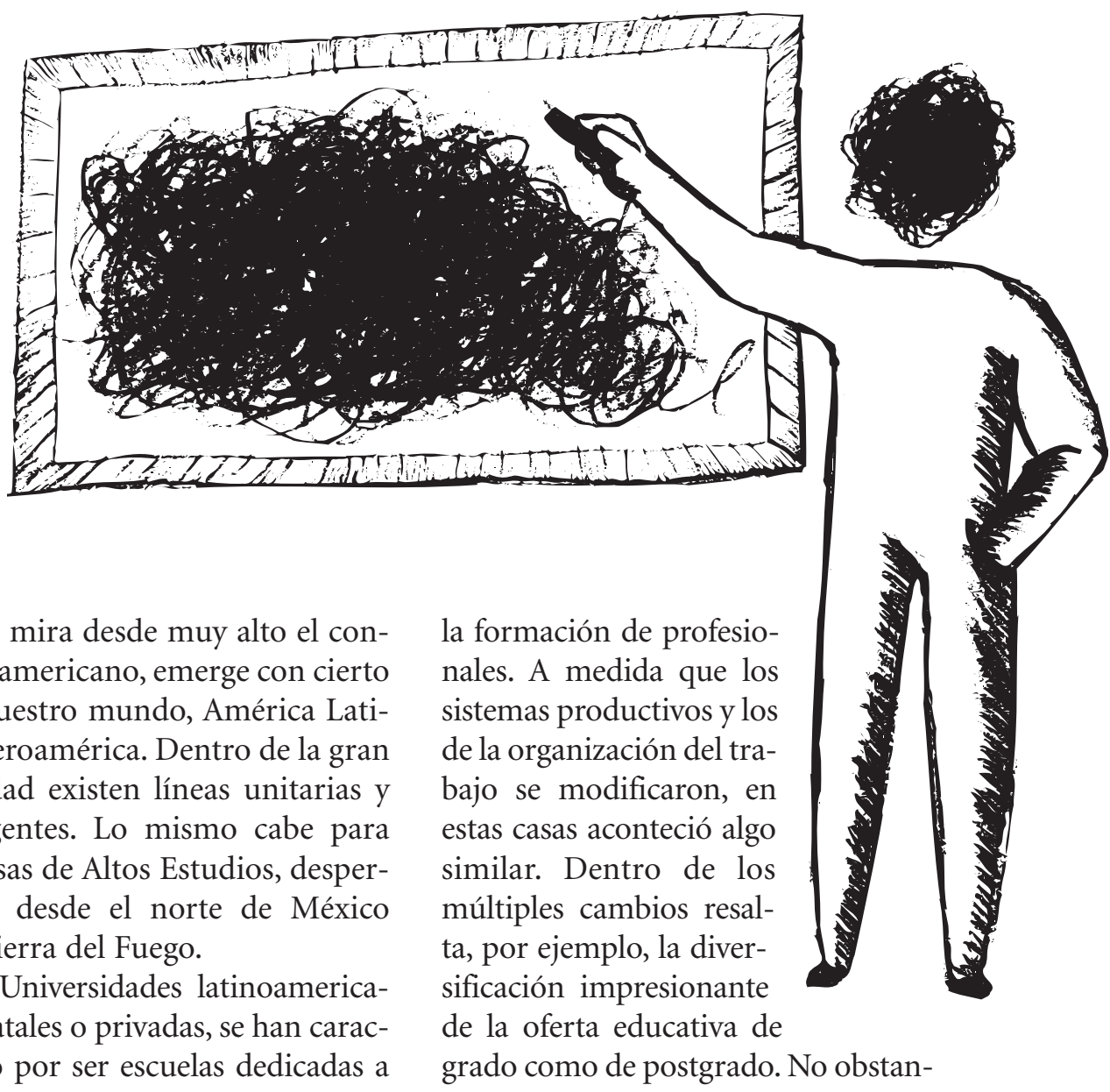

Si se mira desde muy alto el continente americano, emerge con cierto color nuestro mundo, América Latina o Iberoamérica. Dentro de la gran diversidad existen líneas unitarias y convergentes. Lo mismo cabe para esas Casas de Altos Estudios, desperdigadas desde el norte de México hasta Tierra del Fuego.

Las Universidades latinoamericanas, estatales o privadas, se han caracterizado por ser escuelas dedicadas a la formacion de profesionales. A medida que los sistemas productivos y los de la organización del trabajo se modificaron, en estas casas aconteció algo similar. Dentro de los múltiples cambios resalta, por ejemplo, la diversificación impresionante grado como de postgrado. No obstan-

* Catedrático de la Universidad Tecnológica Nacional y Autónoma de Entre Ríos y Director de dos posgrados de Epistemología del Instituto № 13 de la Provincia de Santa Fe, Argentina. 
te no se hace cola en los aeropuertos del mundo desarrollado para venir a estudiar a nuestras instituciones.

El énfasis puesto en la formación profesional, explicable por múltiples razones, desalentó otra ladera: la producción de conocimientos, en particular en el mundo de las ciencias básicas, aunque no sólo en ellas.

\section{Los cambios institucionales, fuertes en la dimensión curricular, se presentan como una exigencia urgente e impostergable.}

Con respecto a la formación profesional es probable que en los estatutos de todas estas Universidades se encuentre un mismo principio: la formación integral de los futuros agentes del cambio y facilitadores de las demandas sociales. Esta declaración de metas, si se analizan los resultados, se ve que posee mucho de retórica, sin saber muy bien de qué se trata en el momento de definir su contenido. La especialización, la fragmentación de saberes, la clausura disciplinar, la feudalización del cono- cimiento profesional, son tópicos relevantes que anulan toda posible integración. Este fenómeno conlleva la imposibilidad de un pensar desde nosotros, y lógicamente, por y para nosotros mismos.

Los saberes no se crean desde la intemporalidad, sino que surgen desde mundos históricos concretos. Y América Latina no se ha caracterizado por ser productora de conocimientos, sino al contrario, una consumidora especializada en ello.

El siglo XXI se presenta incierto y con nuevos desafíos, impensables hace poco tiempo atrás, en todos los campos de la vida pública y privada. Ello lleva a que nuestras casas de estudios se reposicionen, pierdan la rigidez de estructuras viables en un mundo que ya no existe más, se modifiquen en relación a las nuevas demandas y a la creación de un mundo humano digno para los hombres y mujeres de esta América pobre y con voz escasa. Existen excepciones, naturalmente.

En un mundo donde el conocimiento y la información son variables indispensables para el desarrollo, la necesidad de supervivencia ha llevado a replanteos más o menos profundos en las Universidades de Iberoamérica.

Los cambios institucionales, fuertes en la dimensión curricular, se 
presentan como una exigencia urgente e impostergable.

No es fácil la innovación. La inteligencia humana y las costumbres se resisten a los cambios. Más valen las respuestas que las preguntas; si hemos trabajado así, siempre, y con buenos resultados, ¿por qué cambiar?, he escuchado en muchos claustros. Si bien la respuesta no es difícil, a pesar que el problema sea muy complejo, resulta costoso ser persuasivo por más argumentos que se brinden. Hay obstáculos profundos que parecieran obstruir la capacidad de autocrítica, ver el presente tal cual es, y proyectar caminos viables para el futuro.

Dentro de la agenda de la innovación educativa, me limitaré sólo a un aspecto de tan complejo problema, a saber, la formación de los docentes universitarios. Es sólo una pata de la mesa, pero muy importante.

Para evitar toda ambigüedad, lo diré en pocas palabras: si no hay innovaciones en las matrices intelectuales de base del cuerpo docente creo que es muy difícil, sino imposible, toda innovación de largo aliento que esté al servicio de la promoción humana y de un desarrollo sustentable.

Esto nos lleva al tema de este trabajo: las epistemologías implícitas en los docentes universitarios de nuestras casas de altos estudios.

\section{La investigación de un caso}

$\mathrm{He}$ asistido activamente, como profesor de la Universidad Tecnológica Nacional Argentina, a los largos esfuerzos para modificar el modelo de enseñanza de las ingenierías. El diseño llevó su tiempo; más tiempo demoró la aprobación del nuevo modelo. Pero a la hora de la implementación sucedió, durante un largo período, un fenómeno esperable para muchos de nosotros: se modificaron los nombres de supuestas nuevas estructuras y contenidos curriculares pero la enseñanza continuó igual. Se hicieron muchas cosas, pero en lo sustantivo era más de lo mismo. No se preparó a los agentes o actores principales, a saber, los docentes. Así que se perdió muchísimo tiempo.

Este hecho nos llevó a algunos a preguntarnos por las causas operantes en la resistencia a los cambios y a la imposibilidad de llevarlos a cabo. La experiencia y la práctica educativa de muchos años nos condujo a seleccionar una variable e investigarla en los profesores de nuestra provincia en todas las áreas.

El punto de partida fue el siguiente: "el modelo internalizado de lo que es la estructura y dinámica del conocimiento científico, sus alcances y validez, así como los modelos del enseñar y 
aprender tal conocimiento, constituyen un obstáculo para la innovación".

Es pertinente aclarar, antes de describir la investigación realizada, que este caso argentino lo hemos visto operante en muchas instituciones de nuestra Patria Grande, ya sea en Ecuador, Perú, Paraguay, Brasil, Chile. Sería anómalo si sucediera lo contrario. Fuerzas espirituales comunes operaron durante los siglos XIX y XX.

Se llevó un trabajo de campo que duró dos años (1999-2000), comenzando con cuatro cursos intensivos (600 horas reloj de duración) sobre Epistemología de la Educación. 620 profesores de octavo y noveno de EGB y Polimodal, de todas las áreas (con otros términos: profesores del secundario y de los últimos tres años preparatorios para el acceso a la Universidad). Se realizó un pretest inicial que brindó una información como para comenzar a trabajar. Es necesario aclarar que la población seleccionada para el estudio fue un recorte hecho: solamente la integraban los profesores de las instituciones católicas de nuestra provincia, pues se suponía que en tales ámbitos no sería tan fácil verificar nuestra hipótesis. Al ser institutos católicos, por una cuestión de principios, el positivismo y neoempirismo, tendrían alternativas superadoras a nivel racional. En los papeles la cuestión estaba y está más o menos clara.

Luego se seleccionó al azar 228 profesores y se utilizó diversos instrumentos. Con posterioridad y por el mismo camino quedaron 66 profesores, con los cuales se trabajó reflexionando sobre la propia práctica docente. Para ser más riguroso: trabajaron ellos teórica y prácticamente. Como puede advertirse utilizamos en esta investigación técnicas y métodos diversos.

Se consignan algunas conclusiones generales, sin entrar en detalles técnicos.

- La relevancia de la distinción entre teorías explícitas e implícitas en relación a la vida práctica. En el campo educativo el desconocimiento de estos niveles del conocimiento de los profesores impide comprender la práctica real.

- Puede afirmarse, si nos atenemos a este estudio y a otras justificaciones teóricas que trascienden esta investigación, que las teorías implícitas constituyen un sistema de creencias base de la acción.

- Ambos niveles del conocimiento de los profesores requieren métodos y técnicas diversas para la recolección de la información y su conceptualización. Pareciera que este hecho puede resultar explica- 
tivo de algunas faltas de coherencia, en temas puntuales, entre lo obtenido en la 'escala de opinión' y la 'autorreflexión' sobre la propia práctica.

- Las teorías implícitas o sistemas de creencias son resistentes al cambio e incluso permanecen por un período mayor del estudio de disciplinas que las pongan entre paréntesis o directamente las contradigan. Este fenómeno pareciera justificar el divorcio, relativamente común, entre el discurso y la acción.

- El punto anterior tiene su importancia para la evaluación de la capacitación, así como de lo que 'se dice' (en la planificación o en una encuesta, por ejemplo) y lo que 'efectivamente se hace' o "se sostiene en el segundo nivel del conocimiento de los profesores".

- La necesidad de un planeamiento estratégico, a mediano y largo plazo, de la profesionalización docente. Una "suma" de cursos está lejos de asegurar la profesionalización de los educadores.

- Las 'Historias de la epistemología', incluso los debates de la 'Epistemología actual', si bien son saberes que poseen valor en sí mismos, pierden un alto grado de su relevancia si no se los contextualiza en la profesionalización del educador. Por tal motivo se ha ha- blado de la necesidad de una 'Epistemología Educacional'.

- La conclusión central obtenida en la muestra de 208 docentes mediante la 'escala de opiniones' puede resumirse del siguiente modo: "Los docentes encuestados no poseen una noción de ciencia explícita, unitaria y coherente, que guíe de modo consistente y armónico su práctica educativa”.

- Por otra parte, las conclusiones obtenidas en la muestra de 66 docentes (sobre un total de 228 profesores del Tercer Ciclo EGB y futuro Polimodal que respondieron la 'encuesta inicial' que fue utilizada como pretest del proyecto de investigación) pueden dividirse en dos bloques diferentes aunque relacionados:

a) En las conclusiones elaboradas a partir del Pretest, los docentes manifiestan poseer una concepción positivista e inductivista de la ciencia un tanto ingenua, es decir, más o menos irreflexiva y acrítica (conclusión que avala nuestra hipótesis de investigación); a su vez, confiesan la falta de formación básica en Epistemología (y en Metodología de la Investigación) y la necesidad y conveniencia de adquirirla, ya 
que dicha formación es considerada indispensable para adoptar una concepción de ciencia unitaria, explícita, coherente y actualizada, que organice y oriente la práctica educativa concreta. Es decir, que los docentes admiten, la carencia de formación en dichas áreas y la importancia de adquirirla para mejorar la práctica educacional.

b) En otro contexto o en una circunstancia distinta, es decir, en otras condiciones y después de haber realizado el Curso de Capacitación de la Red Federal de Formación Docente Continua titulado: "Epistemología y Metodología de la Investigación", los docentes realizan una "autorreflexión sobre la propia práctica educativa" donde arribaron, por sus propios medios, a las siguientes conclusiones: 1) antes del curso poseían una noción positivista e inductivista de la ciencia, más o menos implícita, que, a contramarcha del discurso epistemológico y didáctico explícito (más innovador, actualizado, amplio y flexible), era quien guiaba la práctica educativa real, no la de- clarada en el discurso, que muchas veces respondía a modas o tendencias intelectuales acríticamente repetidas, pero escasamente internalizadas; 2) después del curso, y del ejercicio de autorreflexión, los docentes se tornan más críticos respecto de la concepción positivista implícita en su accionar áulico, y perciben sus límites, insuficiencias e inadecuación; se vuelven también más críticos de su propia práctica, reconociendo los límites del reduccionismo epistemológico que estructura un accionar educativo igualmente reductivo y estrecho (más informativo que formativo; memorístico y enciclopedista; tal que el alumno era considerado un mero receptor pasivo de contenidos fundamentalmente conceptuales, y no un constructor activo y crítico de conocimiento significativo).

- La criticidad que presentan los docentes, después de efectuado el mencionado 'curso' es producto de una autorreflexión consciente, sincera, muy honesta y radical. Confiesan haber "despertado de un sueño dogmático". Además, antes del curso, no distinguían 
claramente entre "epistemología de la ciencia" y "epistemología escolar", y por ende confundían la metateoría de la ciencia en tanto análisis crítico de los fundamentos, alcance, validez, etc., de los conocimientos producidos por los científicos, con la teoría del conocimiento escolar, es decir, del conocimiento producido, enseñado y aprendido, en el ámbito de la escuela, colegio o Universidad.

En el ejercicio de autorreflexión reconocen la carencia de una sólida formación epistemológica $y$, simultáneamente, la importancia de adquirirla, ya que incidiría positivamente en su práctica laboral o trabajo áulico. En este ítem coinciden plenamente con las conclusiones obtenidas en esta investigación mediante la 'escala de opiniones'.

- La hipótesis central de esta investigación: "En las prácticas docentes de los profesores del Tercer Ciclo EGB y futuro Polimodal de la Región IV de Santa Fe, está supuesta una epistemología que subyace, generalmente originada en una concepción positivista ingenua de la ciencia y del conocimiento", que se consideraba como un obstáculo epistemológico para la actualización disciplinar, y la correspondiente transposición didáctica se ve ratificada plenamente por las consideraciones efectuadas en los puntos a) y b), esto es a partir de las conclusiones obtenidas mediante el Pretest y la Autorreflexión sobre la Práctica docente . Pero dicha hipótesis debería ser ampliada, a la luz de las conclusiones obtenidas mediante la Escala de Opiniones. Esta modificación podría formularse como sigue: "En aquellos casos en que los docentes no poseen una noción de ciencia positivista-inductivista más o menos ingenua, tampoco poseen otra concepción alternativa distinta sólidamente estructurada, explícita, unitaria y consistente, que resultara más innovadora y actualizada que la concepción positivista". La ausencia de una tal concepción alternativa constituye, como se ha dicho, un serio obstáculo epistemológico para la actualización y la transposición didáctica.

Ahora bien, ya sea a partir de la hipótesis original, plenamente confirmada mediante algunos instrumentos o de la hipótesis ampliada a la luz de otro instrumento, creemos que existe el fundamento suficiente para considerar demostrada la necesidad de la formación epistemológica 
(tanto en lo que se refiere a Epistemología propiamente dicha como a Epistemología Escolar) de los docentes encuestados, con lo cual el objetivo principal de esta Primera Fase de la investigación está cumplido.

\section{La Epistemología de la Educación es una disciplina nueva y tiene mucho que ver con el futuro de nuestra tarea y de nuestros sistemas educacionales.}

Una consideración final nos permitirá extraer algunas implicancias de estas conclusiones generales. Una consecuencia derivada de éstas consiste en interpretar la radical honestidad de la autorreflexión llevada a cabo por los docentes, como una actitud de autocrítica de su propio trabajo educativo, pero también, como una actitud crítica del sistema educativo que enmarca, formaliza e institucionaliza estas prácticas. Inclusive la dualidad confesada entre un discurso epistemológico-didáctico en boga, que habla de racionalidad ampliada y teorías innovadoras y actualizadas, y una práctica real que dista mucho de aquel discurso teórico, habla a las claras de que el sistema educativo incurre en una contradicción palmaria entre lo que se exige institucionalmente "en los papeles" (planificaciones, currículos, etc.) y lo que verdaderamente se hace en la práctica educativa. Un claro ejemplo de esta contradicción institucional lo constituye la diferencia radical entre el currículo manifiesto y el "currículo oculto", constituido por las acciones del docente no consignadas en las planificaciones, pero que ejercen una innegable influencia en el proceso real de enseñanza-aprendizaje.

En síntesis, una lectura o interpretación posible de estas conclusiones consiste en extender la autocrítica profesional individual (de cada docente) al plano institucional: los docentes encuestados ponen en tela de juicio tanto su práctica educativa como el sistema que permite e institucionaliza esas prácticas, claramente inadecuadas.

Esta autocrítica valiente que han formulado estos colegas del colegio secundario sobre su acción, y a su epistemología implícita, sería interesante que llegase a los ámbitos universitarios. Mis largos años en este nivel me han brindado la experiencia 
suficiente para conocer esta epistemología implícita, inmune a la crítica. Hasta bien entrada la década de los noventa en muchísimas facultades reinaba soberana, quizás, sin saberlo los actores.

\section{Ciencia, educación y nuevos paradigmas}

La Epistemología de la Educación es una disciplina nueva y tiene mucho que ver con el futuro de nuestra tarea y de nuestros sistemas educacionales. El tema posee escaso desarrollo en América Latina.

No es azaroso que no se cultive este campo indispensable para una innovación educativa de largo alcance.

Es una dimensión de la Epistemología que recae sobre el conocimiento enseñado (propiamente habría que decir "escolar"; adviértase que "escolar" no significa referente al nivel primario o secundario como inmediatamente lo interpretan nuestros hábitos mentales, sino al saber que se crea en el aula). Abarca, pues, todos los niveles y campos disciplinares, desde el nivel inicial hasta la Universidad.

Quizás alguien pueda sorprenderse por el término "Epistemología de la Educación" y piense en algunas ciencias específicas, más particularmente en la pedagogía y la didáctica que también tratan, entre otras cuestiones, el conocimiento escolar. La problemática abordada en este trabajo es de índole epistemológica. Al que está habituado a escuchar y categorizar a la Epistemología como Teoría de la Ciencia, o Metaciencia, como es común en la literatura hispana ( $y$ en el mundo latino), el término puede sonarle un poco extraño al comienzo. Ha acontecido que el campo de la Epistemología, en estas dos últimas décadas, se ha ensanchado de una forma impresionante hasta adquirir dimensiones que resultaban insospechadas hasta hace poco tiempo atrás.

Existe en la actualidad, un abismo insalvable entre la escuela y "el mundo de la vida" 1 si se continúa por los andariveles recorridos por

1 El término "mundo de la vida" fue acuñado, como se sabe, por Husserl y luego desarrollado por su discípulo Alfred Schutz. En los diversos capítulos, de forma espiralada, se tratará sobre el significado y alcance del mencionado término para redefinir de este modo el conocimiento cotidiano, y de allí el escolar y las posibles alternativas para su desarrollo, siempre en el orden de los fundamentos, y no sobre los pasos sobre como llevarlo a cabo. Esto pertenece a otro ámbito, a la tecnología gestional, más específicamente a la didáctica. El término o categoría mundo de la vida, es tomado de la fenomenología, pero sin ataduras a la conceptuación que la misma ha llevado a cabo sobre el tema. 
décadas y décadas. Una de las tantas manifestaciones es el desprecio del conocimiento que surge de ese mundo que, no obstante, es la morada donde efectivamente vivimos, sufrimos, amamos y morimos los seres humanos, por parte del pensamiento académico. De allí emerge el conocimiento cotidiano. ¿No abunda todavía en muchísimos textos la caracterización del conocimiento científico como opuesto al conocimiento cotidiano, llamado vulgar, con los calificativos y valoraciones por todos conocidos?

En la década de los setenta y ochenta la profunda crisis de las ciencias empírico analíticas y de las ciencias sociales lleva a la gestación de lo que se ha llamado ciencias críticas. (Hay que optar por alguna clasificación de las ciencias para poder entendernos, sin que ello signifique compromiso teórico definitivo). Dentro de ellas, pero bajo un nuevo paradigma profundamente distinto al de la modernidad, aparece la Nueva Epistemología. Cuando Edmund Husserl publicó el clásico libro: "La crisis de las ciencias europeas y la fenomenología trascenden- tal"2 -de profunda influencia en el pensamiento posterior- causó cierta sorpresa el hablar de "crisis de la ciencia", cuando en realidad lo que se evidenciaba era su asombroso desarrollo. Asimismo, hoy puede originar alguna perplejidad en reducidos ambientes volver sobre la misma cuestión. Claro que desde Husserl hasta hoy ha corrido mucha agua bajo el puente, ya sea en el campo de las ciencias como en el de la filosofía. El problema es más profundo, de lo que planteó el ilustre filósofo alemán, pues él dejó intacta la metodología y la consistencia interna de las ciencias. Puso en el debate sólo su pretensión de totalidad.

También es comprensible en el ambiente de los tecnólogos de habla hispana el que aún no haya ingresado de forma abierta esta problemática. El feed-back entre tecnología y ciencia es manifiesto, $y$ hasta resulta dificultoso demarcar las fronteras entre las mismas; sin embargo, son racionalidades diferentes. De allí que lo sean sus estructuras lógicas así como sus dinámicas de desarrollo. También la epistemología educacional tiene un capítulo bastante desarrolla-

2 Husserl, E. “La crisis de las ciencias europeas y la fenomenología trascendental”, Folios Ed., México, 1977. "Die Crisis der europäischen Wissenchaften und transzendentale Phänemonologie" (1936). Para comprender mejor el contexto quizás haya que recordar que siete años atrás el famoso Círculo de Viena había publicado su manifiesto:"La concepción científica del Mundo". 
do sobre este tópico, aunque es muy escaso en América Latina ${ }^{3}$.

La crisis de los conceptos de razón, ciencia, ley, teoría, verdad científica, método, entre otros, operada en el transcurso de estos últimos cincuenta años, ha repercutido de forma directa en lo que técnicamente se conoce con el término conocimiento escolar.

Lo que se ha puesto en tela de juicio es pues el conocimiento enseñado tal como fue comprendido por la modernidad y la mayor parte del siglo XX; hay que tener en cuenta que los cambios en educación son muchos más lentos que los operados en el seno de la comunidad científica y tecnológica y de las exigencias de los administradores y gestores de las políticas en educación.

La Epistemología de la Educación lleva a replantear los modos tradicionales de enseñanza, esencialmente repetitiva y mnemotécnica para intro- ducir en el concepto mismo de enseñanza-aprendizaje las ideas de innovación e investigación, dentro de las cuales se hallan las numerosas propuestas realizadas por pensadores, filósofos, didáctas y expertos en educación. Pero ello como consecuencia de cuestiones primarias, como se verá en el libro, especialmente el conocer inteligente y su relación con la realidad.

De forma lenta pero creciente, se va imponiendo este nuevo recorte de la conocida Epistemología General, y de las específicas que quedaban encerradas en los campos científicos. El conocimiento humano es mucho más complejo.

Este campo cognoscitivo se cruza, como puede advertirse rápidamente, con diversos saberes como la didáctica, la pedagogía, la psicología, la sociología del conocimiento, la historia del pensamiento ${ }^{4}$ y de las ciencias, la historia de la cultura ${ }^{5}$ y con diversas

Pueden consultarse al respecto, entre mucha otra bibliografía, los últimos escritos de Mario Bunge y del Centro que dirige en Canadá. Al decir mucha bibliografía hago referencia a las áreas, Centros, Institutos de la conocida sigla CTS, que están editando trabajos, Revistas de las Universidades de la Comunidad Económica Europea. El caso de España es particular; los que yo conozco, fecundos por cierto, están compuestos por sociólogos, economistas, filósofos. Falta una pata. Es vieja la historia y no se puede pedir que un manzano de cerezas.

4 Se utiliza la expresión “historia del pensamiento",y se la distingue de otros tipos de saberes históricos, pues aquella trata sobre las ideas, filosóficas, científicas, o no, relacionadas con la dinámica del tiempo. Existen algunas "Historias del Pensamiento"; lo que abundan son las clásicas "Historias de la Filosofía,"'o de la ciencia", así en abstracto.

5 Para mayor exactitud debo decir: Historia y Ciencias de la Cultura. Historia de la Cultura es aún un término ambiguo. En este texto, se entiende a la cultura como una estructura sistémica con una dinámica histórica particularísima. Dentro de este universo simbólico la educación es un subsistema relevante con muchos niveles, actores y factores que se relacionan. 
disciplinas filosóficas, entre otras. (Para los latinoamericanos, fuertemente formados en las asignaturas disciplinares, casi sin historia, salvo algunos datos iniciales irrelevantes conforma esto una dificultad y una laguna seria; pues otorga sin querer una visión distorsionada del conocimiento, como si fuese ahistórico).

Por tal motivo en el texto se han introducido las líneas del pensamiento clásico, medieval, moderno, y contemporáneo. Resulta necesaria, no como adorno de la mente, la comprensión histórica de los grandes paradigmas dentro de los cuales se recortan los distintos modelos epistemológicos.

Desde lo dicho resultan comprensibles las dificultades de los docentes para emprender acciones de innovación e investigación en el aula y su actitud resistente a los cambios. Desde la epistemología subyacente, es lógica tal actitud como se verá a lo lar- go del trabajo. El conocer inteligente tiene sus exigencias. El pensar crítico posee senderos propios, no es maná que cae del cielo.

Es necesario destacar que la tarea se lleva a cabo desde un a priori antropológico: América Latina como único horizonte de comprensión ${ }^{6}$. De lo contrario el riesgo de la alienación, repitiendo discursos ajenos, es casi imposible de soslayar.

El pensar por nosotros mismos es una exigencia indelegable. Nadie lo hará por nosotros, ya sea en el campo de las ciencias, la tecnología y la filosofía. Como en otros ámbitos de la cultura. La educación es un subsistema crucial para un desarrollo factible, sólido, de largo alcance. Por este motivo el trabajo de los docentes en una dimensión de sus inteligencias parece crucial a los fines de superar los obstáculos epistemológicos arraigados y con una larga trayectoria, que ya es tradición.

Deseo enfatizar el término "horizonte de comprensión", para evitar equívocos que a menudo imperan en ambientes intelectuales, donde también las modas tienen sus vigencias. En primer lugar no me refiero a un "perspectivismo" de la realidad, donde ésta se oculta por la primacía de la perspectiva; ni tampoco a posturas bastante extendidas en América Latina; frente a Europa, o a sus proyecciones, están a la defensiva (de allí, diversos tipos de telurismos), o posiciones que prescinden de entrada de lo "local", de la cultura donde se mora. En éste último caso el pensamiento latinoamericano se guía por el último librito que se ha editado en Europa o Estados Unidos; entonces se repiten un poco alegremente los "post" (modernidad, ciencia, filosofía etc.). El "actualismo" es una enfermedad (alienación) que con esfuerzo puede evitarse. En relación a Europa, su periplo espiritual zigzagueante, recorrido en diversas instancias, puede y debe ser asimilado por nosotros, hasta donde en realidad podamos. Es un periplo espiritual imponente y hay que bucearlo en sus fuentes. En mi libro "América Latina, liberación y filosofía", editado por la Universidad Andina Simón Bolívar de Ecuador, se aborda esta temática. 


\section{La profesionalización docente: asignatura pendiente}

Hace poco Rafael Porlán Ariza publicó un artículo sobre este tema en el diario "El País" de Andalucía (5-52005) donde hacía un severísimo llamado de atención. Es notable el eco que tuvo. No basta para ello con la merecida fama del autor si la sensibilidad de los docentes no estuviese a flor de piel. Lo que en España se ve como una asignatura pendiente, aquella realidad es muy distinta a la nuestra (con pocas horas frente a alumnos, con sueldos que permiten vivir y comprar libros, con las horas pagas para reuniones entre profesores, con los padres para realizar tutorías a alumnos etc.). Aquí, la capacitación docente es una realidad que hiere y duele. Tradicionalmente ha estado ausente de forma casi absoluta, dejada a la iniciativa individual. ; Si enseñar enseña cualquiera! ¡Es tan sencillo! O era.

El tema de la calidad educativa corre paralelo al de la "profesionalización docente”. Prácticamente en casi todo el mundo se ha discutido y se debate esta última cuestión desde distintos tópicos e intereses. Pero un pequeño error en los principios lleva a graves errores en las conclusiones, como dijo Tomás de Aquino siguiendo a Aristóteles. En nuestro caso, una inteligencia con falta de suficiente claridad para el diagnóstico (no para la descripción de sus síntomas, sino para determinar sus causas) ha conducido a no pequeños errores y lagunas en diseños curriculares, así como en proyectos de capacitación. Aunque es inadecuado hablar en términos absolutos. Ya hay experiencia y es bastante lo que se ha hecho, con resultados diversos.

La profesionalización del docente no es una tarea cualquiera, ni una obra de un día, ni siquiera de un gobierno. Se necesita mucho tiempo. Para referirme sólo a nuestro tema, que es condición necesaria aunque no suficiente para una innovación de calidad, la comprensión-histórica de la ciencia, su valor, relación con la vi$\mathrm{da}$, ha llevado generaciones y generaciones sin tratamiento. $\mathrm{Y}$ como ha existido una mutación en este punto los hábitos largamente practicados no se renuevan por decreto ni por programas de "reconversión". El ser humano es algo demasiado serio y profundo; no es manipulable.

Como quizás ya pueda percibirse la epistemología de los docentes posee una relevancia de primer orden en relación a la calidad de los procesos y resultados. Eso, por un lado. Si la mencionada epistemología es una de las variables que, hoy, lleva al fracaso del conocimiento escolar, surge de inmediato la pregunta sobre qué nuevas lí- 
neas epistemológicas habrá que diseñar para la educación del futuro, en particular. Alguien podría, quizás, objetar que la referida epistemología implícita no fue obstáculo para el conocido y cualitativamente ventajoso sistema educativo de otros tiempos en algunas regiones de Latinoamérica. Es verdad. Pero se trata de otros tiempos. Por otra parte no hay que absolutizar los juicios. Una escuela primaria relativamente buena, donde se aprendía a leer, escribir y las operaciones matemáticas elementales. Un colegio secundario un poco más "light"; pero la disciplina y algunos hábitos de lectura eran habituales. Y en la Universidad, sí sobresalían varias y excelentes facultades. No obstante lo dicho, los países latinoamericanos en esta época floreciente no crearon las bases para ser productores de conocimientos, sino que siguieron el modelo de región consumidora. A otros les correspondió el rol de ser productores del saber que servía de valor agregado para nuestras materias primas.

Pero lo dicho ya pasó. Y la historia trae nuevos desafíos y exigencias.

La Reforma Educativa de nuestros países, así como ha sucedido prácticamente en todo el mundo, ha tocado la cuestión de la profesionali- zación del docente: su alcance, validez, motivos que la originan, incluso su sentido. Actualización y perfeccionamiento continuo, reconversión, acreditación, son algunos de los términos corrientes que se han impuesto de forma pública.

Es conveniente enfatizar cómo los nuevos escenarios mundiales han repercutido de forma honda en los sistemas educativos de regiones y Estados nacionales. Paradigmas educativos pensados para un pasado, hoy en gran medida inexistente, han entrado en un proceso de crisis acelerada.

¿Es verdadera la opinión, se preguntaba hace tiempo un experto ${ }^{7}$, que la educación enfrenta hoy el desafío de su actualización sin la cual corre el riesgo de perder toda significación social?

No se pretende resolver aquí este problema. Su simple planteo pone de manifiesto el descontento en relación a la calidad de procesos y resultados de una actividad que todo el mundo reconoce como indispensable para la promoción humana y la generación de las bases de un desarrollo sustentable. Claro, hay que hablar en términos bicondicionales: si, y sólo si la educación responde a las necesidades de los nuevos tiempos. 
¿Acaso en este mundo en permanente mutación no es necesario un proceso de alfabetización (incluidos los docentes), en muchísimos saberes que son indispensables para la adaptación activa a los nuevos escenarios, y especialmente, para gestionar una educación de mejor calidad?

Una simple mirada para atrás detecta que la "profesionalización del docente", con la capacitación continua no era una realidad que se imponía. A lo sumo, en aquellos casos cuya titulación era ajena al campo educativo, unos cursos de pedagogía y didáctica pretendían llenar un evidente vacío con los resultados sabidos.

Cuando se habla de la profesionalización del docente, la literatura producida en esta última década señala un serio avance. Resulta indiscutible la necesidad de la actualización disciplinar, las competencias que brindan los saberes de las ciencias y tecnologías de la educación, el manejo de las nuevas tecnologías de la comunicación e información.

Pareciera que la profesionalización docente pasa por lo menos por cinco ejes:
- La actualización disciplinar

- La capacitación para un trabajo interdisciplinar

- La formación en miradas metadisciplinares

- La utilización de las nuevas tecnologías informáticas y de la comunicación (NTIC).

- La adquisición de competencias para la investigación y desarrollo educativos.

Si se ahonda en el tercer eje se llega a la formación epistemológica.

Creo que con ella no es suficiente ${ }^{8}$. Pero ya es un gran paso adelante. Son conocidos los intentos que se han llevado a cabo, por ejemplo, en Argentina, para llenar este vacío, valiosos por cierto en sí mismos, no tanto para los cambios.

Estoy convencido, por los estudios y la práctica, que las necesidades demandan una reflexión sistemática sobre la propia práctica docente, poner al descubierto las epistemologías implícitas, la reconstrucción de un saber acerca del conocimiento escolar, sus fuentes, validación, sentido y 
alcances, vinculación y retroalimentación entre la teoría y la práctica, y cómo relacionarlo con las experiencias vitales de los alumnos. Para ello es innecesaria la clásica epistemología general de tantos textos, valiosos en sí mismos, para entendidos en filosofía; se necesita un recorte especializado de la misma. Por esta senda se puede empezar a suturar la brecha entre el aula y el mundo de la vida, comenzando por la inteligencia de los profesores.

\section{Paradigmas educativos pensados para un pasado, hoy en gran medida inexistente, han entrado en un proceso de crisis acelerada.}

Con lo dicho se han tocado dos puntos importantes. Sólo dos. La profesionalización del docente en relación a la dimensión cognoscitiva, en sus ámbitos teórico y práctico. El conocer inteligente de los docentes y alumnos se tensa ante la presencia enigmática de los valores, el valor verdad, y otros esenciales para una existencia gozosa.
Sin esta pata la profesionalización docente carece de un motor que debe conectar la educación al mundo de la vida. Reitero: llevará tiempo, pues los principios organizadores de nuestros sistemas educativos llevan más de un siglo de vigencia.

\section{La educación latinoameri- cana y el tema de su calidad}

Un rápido mapeo por nuestro mundo latinoamericano permite la determinación de sus desafíos, semejanzas, y en algunos casos, profundas asimetrías. De forma genérica puede consignarse nuestra tendencia a la repetición y a la copia. Sin embargo hay países que en estas últimas décadas han apostado fuerte a la transformación educativa, como es el caso de Cuba, Brasil, Chile, México, para mencionar a los principales. Ya es posible ver sus frutos. Argentina que fue pionera en un tiempo se quedó en discusiones.

Sorprenden ciertos rasgos generales comunes. ¿Quién pone en tela de juicio el escaso nivel de lectura, manejo del lenguaje oral y escrito, desubicación histórica, entre tantas otras lagunas de nuestros chicos, adolescentes y jóvenes, incluidos naturalmente los universitarios? Si nos asomamos al pensar matemático, (no hablo del manejo nemotécnico 
de las operaciones de análisis ni de las reglas de las operaciones lógicas), o a la comprensión del mundo natural, cada vez más exigente en sus niveles de modelización, el panorama resulta desolador.

De allí al intento de hallar con cierta rapidez a los culpables hay un paso. A menudo quien primero cae es la vieja escuela media, y no soy yo quien intente hacer de abogado del diablo. La escuela media encuentra en la primaria las falencias. La primaria en la ausencia de "bajada de líneas claras" y especialmente en los padres. La responsabilidad siempre la tiene el otro. Y quienes están en el nivel universitario miran los niveles inferiores como los responsables directos, y a menudo, la autopercepción falsea toda la realidad, especialmente la propia.

Una mirada sobre el proceso de la educación en estas últimas décadas en nuestra región permite destacar los acelerados cambios producidos en múltiples aspectos, particularmente en su función teleológica. Algunos términos muy usados son ilustrativos y permiten una visión de síntesis: la educación como motor del desarrollo (década del sesenta), la educación como justificación del status quo y como proceso liberador (años setenta), la educación para el orden (fines del setenta y principios del ochenta), la educación para la democracia (década del ochenta), la educación para las competencias y para la calidad en un mundo globalizado y competitivo (década del noventa). Estas modificaciones de orientación esencial, pues afecta uno de los principios integradores de la educación, han tornado dificultosa la ubicación de los educadores que se han visto jaqueados por ideologías contrapuestas. Del mismo modo han tornado casi imposible un planeamiento a mediano y largo plazo, así como el perfeccionamiento y actualización docentes sostenidos.

La calidad cuestionada de la educación argentina, (hablo de ella por los datos precisos que poseo) desde el primer nivel hasta la Universidad, constituye un fenómeno social innegable. En una encuesta realizada a quienes ingresan a la Universidad Tecnológica, el $89 \%$ opinó sobre la escuela media como "pérdida de tiempo" con respecto al estudio9. Pero el mismo fenómeno puede leerse en Honduras, Paraguay, Ecuador, FRSF). 
Colombia, o cualquier otro país latinoamericano.

Los escasos estudios llevados a cabo sobre los egresados de las Universidades manifiestan el mismo fenómeno: la profunda disconformidad con la formación profesional, juzgada como teórica, con una multiplicidad de informaciones inconexas e inservibles. En este último tiempo algo se está produciendo en varios países latinoamericanos ${ }^{10}$. En mis estancias en Universidades de nuestra Patria Grande no necesitaba estudios empíricos: la queja o lamento escuchado de los jóvenes y directivos era fuerte y generalizada, como también la decisión de cambio de rumbo. Pero a menudo faltaban ideas de cómo comenzar y qué hacer.

No es fácil. Nada fácil. El fenómeno es complejo e intervienen muchas variables.

Una de ellas es la formación profesional de los docentes y la necesidad de su actualización disciplinar, así como la adquisición de metasaberes sin los cuales la educación pierde su orientación, sentido, e incluso calidad en la modalidad concreta de implementación.

Uno de estos metasaberes, como se ha consignado, está constituido por la formación epistemológica tradicionalmente ausente en la preparación de los profesores y maestros.

\section{Necesidad de la formación epistemológica}

Las innovaciones educativas, además de presupuesto, políticas pertinentes, y modelos que guíen la innovación, necesitan de insumos de conocimientos sobre la realidad a modificar.

El perfeccionamiento docente, para ser sistemático y que apunte a los nudos críticos, requiere de un saber sobre las necesidades y demandas; y ello no de una forma genérica, sino que tenga un grado de especificidad sobre las fortalezas y vacíos concretos.

10 En estos tres últimos años se vienen realizando diversas investigaciones sobre esta problemática. Puede consultarse a las Secretarías de Ciencia y Tecnología de las distintas Universidades, o los Organismos pertinentes del Ministerio de Educación y Cultura de la Nación. Personalmente voy juntando un precioso material sobre cómo ven los alumnos de los últimos años de algunas carreras el proceso de enseñanza aprendizaje que han llevado a cabo desde sus primeros años hasta la actualidad en la que están finalizando sus estudios de grado. La muestra no es al azar, sino que se han seleccionado cuidadosamente centros de alta calidad educativa, que los hay, por supuesto. Junto a ello poseo una muestra, al azar, de 600 profesores de una provincia importante, de diversas disciplinas, sobre cómo ven su propia práctica educativa, as como la vigente en el contexto institucional. El material de los alumnos creo que es para editarlo sin mayores modificaciones, salvo una conceptualización y sistematización de resultados. La claridad es meridiana. 
No es novedad decir que la investigación educativa en Iberoamérica es escasa, con excepción de unos poquísimos países. Pero algo se ha hecho en esta década. No hay tradición al respecto. Como tampoco la hay en Investigación y Desarrollo; aunque en tal contexto sobresalen nuestros premios nobeles y algunos Centros y Fundaciones de excelencia dedicados a la investigación. Pero como línea general sigue siendo verdad lo que estudiosos vienen afirmando aproximadamente desde la década del sesenta: somos consumidores de ciencia y tecnología, no productores. Larga y compleja es la historia.

Dentro de este amplísimo campo de la educación hay un área de la que se habla bastante, a saber: qué visión tienen los profesores acerca del conocimiento científico, de su estructura lógica y dinámica histórica, formas de validación de leyes y teorías, límites, retroalimentaciones y su intrínseca relación al conocimiento escolar que se desarrolla en el aula, laboratorios y espacios prácticos ad hoc.

El fenómeno de la crisis de la calidad y ausencia de una formación epistemológica de los profesores no es privativo de América Latina. Tam- bién lo ha sufrido y lo sufre Europa, como es, por ejemplo, el caso de España a pesar de los variados intentos que ha llevado a cabo por cualificar los estándares de calidad. Ha recorrido mucho camino al respecto, y en algunas áreas nos llevan kilómetros de ventajas. Sin embargo, es dable observar en muchas facultades españolas la vieja feudalización del saber, así como la clásica dicotomía entre ciencias de la naturaleza-tecnología, por un lado, y Humanidades y Ciencias Sociales, por otro, como si no existiesen entre ellas nexos comunicantes y no tuviesen todas su lugar en la formación de los profesionales del futuro; y por supuesto la tradicional división entre la teoría y la práctica, particularmente en las ciencias básicas, donde la práctica es concebida como simple evidencia y justificación de lo que se ha desarrollado en las clases teóricas. La referencia al caso español la hago simplemente por tener cierta experiencia directa, pero lo mismo puede decirse de muchas Universidades e Institutos del mundo.

Ya en 1970, Elkana afirmaba que la comprensión de los profesores va unos 20 ó 30 años por detrás de los desarrollos de la Epistemología ${ }^{11}$. 
Muchos estudios y documentos de Asociaciones educativas de Europa y EE.UU. sostienen lo mismo desde la década del sesenta; pero en casi todos estos países se han implementado fuertes acciones para superar las falencias referidas.

Lo que señala Hodson (1985)12 también tiene validez para nuestro ámbito (como para toda América Latina): "Una importante consecuencia de la metodología inductivista de la ciencia, implícita en muchos currículos, es la proyección de una imagen distorsionada de la ciencia como actividad neutral, impulsada sólo por su propia lógica interna y funcionando independientemente de cuestiones socio-histórico-económicas y de una visión distorsionada de los científicos como personas objetivas, de manera abierta, sin sesgos, y poseedoras de un método poderoso e infalible para determinar la verdad sobre el universo. "Estos mitos sobre la ciencia y los científicos son interiorizados por los profesores durante su propia formación científica y, por ello, les son transmitidos a los niños por medio del currículo".

Además del "a priori" antropológico de este trabajo, ya enunciado, es pertinente enumerar algunos otros que faciliten la lectura.

La práctica docente supone una epistemología subyacente, implícita o explícita, de forma inexorable.

- Existen nuevos paradigmas en la estructura y desarrollo del conocimiento científico que exigen cambios en los sistemas educativos.

- Es necesaria una formación epistemológica de los docentes, que sea coherente con los paradigmas anteriormente mencionados. "Sea cual sea el enfoque adoptado (transmisión indirecta o explícita de la filosofía de la ciencia), es evidente que los profesores de ciencias necesitan comprender, en alguna medida, cuestiones sobre Filosofía de la Ciencia y sus relevancias para la educación científica, y ha habido muchas demandas para que se preste más atención a tales materias en la formación inicial y permanente del profesorado" (Hodson, D.; 1986; el artículo de este autor trata sobre la formación epistemológica necesaria a los profesores de "ciencias de la naturaleza", sin entrar, ni excluir, a

12 Hodson, D. "Philosophy of science, science and sciene eduaction",en Studices in Science Education, 15 pp. 25-26. 
otros campos científicos) ${ }^{13}$. Tal afirmación tiene validez para los docentes de todas las áreas.

- La metodología de la investigación es un instrumento aplicable a estructuras, procesos, currículos, enseñanza disciplinar, entre otros campos, que puede retroalimentar la enseñanza y el aprendizaje.

- La investigación educativa, un flexible desarrollo curricular y una cualificación profesional permanente de los docentes, coordinados en un mismo proceso, causan niveles de mayor calidad. Lo contrario es repetición de viejos modelos, de la misma manera, con los defectos y virtudes conocidos.

\section{El saber epistemológico: entre la moda y la necesidad}

Es sabido cuándo y cómo se abrieron las compuertas para el ingreso de la Epistemología a las instituciones educativas argentinas. Algo similar sucedió en muchos países hermanos. Aquí vino como un torrente. Hay razones que explican el fenómeno. Se debe esperar que la historia larga se pronuncie al respecto.
El "actualismo" epistemológico me parece negativo por el lado que se lo mire. En general, nada dice, pues carece de contenido. Palabras grandilocuentes: recorte, encuadre, marco, horizonte epistemológicos, entre tantos otros.

No sigo esta senda. No conduce a ningún lugar.

Vuelvo la atención al aula. ¡Cuántos procesos cognoscitivos se dan allí! Ya los analizaré en su momento.

Observo por un momento al profesor o maestra/o antes de ingresar al aula. Va pertrechado con un complejo de ideas acerca de la ciencia, de su valor e importancia, de sus límites si los tiene. Lo contrario es un contrasentido. No existe.

Todo docente posee una epistemología implícita, como ya dije. Agrego ahora: constituyen ideas reguladoras de la práctica.

Por tal motivo aparece la necesidad de hacer el tránsito de lo implícito a la reflexión, el ingreso al pensamiento crítico. Estamos en el campo de este trabajo.

Es una tarea necesaria. En tal caso, quizás como profesionales de la educación se pueda acordar, o no, con ciertos puntos básicos aceptados

13 Hodson, D."Rethinking the role and status of observation in science education,"en "Journal of Curriculum Studies", 18, p.p. 381-382. 
por los investigadores del complejo fenómeno educativo y epistemológico acerca del saber científico.

\section{Señala Hodson:}

“...Mientras es evidente que de la consideración de la literatura (actual) no emerge ninguna visión simple y universalmente aceptada de la ciencia, sí hay un cierto acuerdo sobre un número de puntos relevantes para el currículo escolar:

“(1) La observación depende de nuestras percepciones sensoriales, las cuales son, a veces, inadecuadas $y$, pueden ser falibles y carentes de fiabilidad".

“(2) La observación depende de la teoría y a menudo la teoría, aunque no siempre, precede a las observaciones".

“(3) La ciencia utiliza frecuentemente la observación indirecta y ésta, a su vez, depende de una teoría de la instrumentación".

“(4) La observación no proporciona acceso automático a un conocimiento factual seguro, se ha de interpretar a la luz de las creencias teóricas actuales".

"(5) Los conceptos y las teorías son producidos por actos creativos de abstracción e invención. No surgen directamente de la observación por un proceso de generalización inductiva".

"(6) Las teorías se justifican frecuentemente post hoc por la evidencia experimental, pero para que se acepte una teoría debe haber una (concebible) evidencia que la apoye.

“(7) Las teorías rivales pueden dar lugar a observaciones diferentes cuando se confronta el mismo fenómeno".

“(8) El conocimiento científico sólo tiene un estatus temporal. Los conceptos y las teorías cambian y se desarrollan; algunas se rechazan".

"(9) La inducción es inadecuada como descripción del método científico y por eso los métodos de aprendizaje por descubrimiento que emplean a menudo los profesores de ciencias proyectan una imagen distorsionada de la ciencia" 14 .

A lo dicho por Hodson, orientado al campo de las ciencias empírico-analíticas como si fuesen las modélicas, habría que agregarle que las ciencias hermenéuticas poseen otra metodología de validación, objeto y finalidad. Y que el saber crítico no finaliza con las ciencias hermenéuticas.

14 Hodson, D. "Filosofía de la ciencia y educación científica" en el libro "Constructivismo y enseñanza de las ciencias", compilado por Porlán, R., García, E. y Cañal, P., Díada, Sevilla, 1997. 
Cabe la misma observación para el conocimiento escolar y sus matices diferenciales. La distinción con el conocimiento científico es manifiesta. Sin embargo, y esto es notable, hace poco tiempo que se le ha prestado atención a su peculiaridad, como lo demuestran las investigaciones de la década de los noventa, y especialmente las de estos últimos cinco años. Por tal razón la epistemología sobre este tipo de conocimiento posee un desarrollo incipiente.

La transmisión de la ciencia, como un conjunto de verdades dogmáticas, tiene su historia y justificación en teorías que pertenecen al pasado y no por ello menos vigentes. Un gran matemático amigo me decía: "enseñamos las ciencias como si fuesen una religión". Y tiene razón: los principios de las ciencias, o los axiomas de los sistemas formales, deben ser aceptados para poder continuar. Y si la continuación se la enseña como resolución de problemas, nunca vistos o pensados, lo que se aprenden son verdades reveladas. Muy grave, por cierto.

Por tal motivo, el perfeccionamiento docente que conduzca a un discurso abierto, interdisciplinar, y con una mirada metadisciplinar superadora de la feudalización de los saberes, necesita de esta capacitación con consecuencias en el campo de la educación. ¿Acaso no palpamos todos la fragmentación de las disciplinas, en asignaturas cerradas en sí mismas? ¿Cómo superar las asignaturas islas?

Asimismo la adquisición de competencias para realizar investigaciones educativas parecieran constituir una necesidad impostergable, ávida cuenta de nuestra escasa tradición en este orden y producen conocimientos útiles para un cambio cualitativamente mejor; además de permitir una mayor autoconciencia de nuestra tarea, propósitos esenciales, obstáculos, y vías de superación.

\author{
Es sabido cuándo \\ y cómo \\ se abrieron las \\ compuertas para \\ el ingreso de \\ la Epistemología \\ a las instituciones \\ educativas argentinas.
}

\section{Colofón}

Las Universidades latinoamericanas se enfrentan en el siglo XXI a fantásticos desafíos. 
En el tópico que hemos abordado, una Universidad crítica, con los pies arraigados en nuestro mundo, deberá producir un cambio en los principios epistemológicos que sustentan la acción educativa. Para ello la capacitación de los docentes es una de las tareas de largo aliento.

Las relaciones del docente con el conocimiento en el siglo XXI serán muy diferentes a las que hoy tenemos como "normales". Es otro tema para desarrollar.

Nos toca vivir en el filo de dos épocas diferentes. Por ello, una es la relación que el docente tiene con el conocimiento y probablemente otra sea la que advenga con la sustitución del paradigma iniciado en la modernidad. Lo dicho se infiere de las tendencias psicológicas, educativas, epistemológicas, tecno-científicas y filosóficas de la actualidad.

No es posible el diálogo entre "fides" et "ratio" con la epistemología implícita del positivismo, pensamiento maduro de una Europa que se piensa a sí misma. No somos europeos, aunque participamos de esa venerable e imponente tradición. 